\title{
Investigating the Usability of Universities' Websites: Upgrading Visualization Preference and System Performance
}

\author{
https://doi.org/10.3991/ijim.v16i02.23707 \\ Lilian Lee Shiau Gee, Jakaria Dasan ${ }^{(凶)}$, Che Hasruddin Che Hasan \\ Universiti Malaysia Sabah, Sabah, Malaysia \\ jakaria@ums.edu.my
}

\begin{abstract}
The usefulness of a web site is based on the prospect of a satisfactory website user. In improving the usefulness of a university's website, it is essential to present precise data and disseminate prompt information to students. This paper was conducted to analyse and recommend a better process for the information display (content and work processes) of university websites development. Questionnaires were distributed and feedbacks were received from 350 respondents. The aim of the study was to evaluate the effectiveness of the process of (content and processes) of the university websites based on five main aspects: i) Content and Organization Structure, ii) Linkages and Navigation, iii) Language, iv) Education Content and v) Option and Performance. Analysis showed that the percentage of question items has a positive tendency in perception regarding improvements need to enhance the intensity of the university website portal, especially in terms of links, content organization and live help desk requirements that can directly provide an easier means of that can providing information and accelerating up the operation of receiving data. In summary, this study also outlines the proposal for academic websites display to increase the serviceability of the site to users.
\end{abstract}

Keywords—web usability, website, interface, educational website, user's preference

\section{Introduction}

A website is a content and web page collection that uses a combination of different content, such as text, video, audio, images and other digital content. Web sites serve a fast and easy delivery mechanism to a large group of users [5]. As such, websites play an important function as a source of service that enables organisations to interact with their stakeholders [34]. In our ever-globalised world, websites play an important role in the growth of an organization, in which website is able to represent the organization's values, communicate the vision and mission of the organization and facilitate the various tasks that the organization needs to perform to its stakeholders.

It is import to ponder that the website is a platform for universities to communicate, collaborate and disseminate information to various parties (faculty, academic staff, 
administrative staff, students, alumni and visitors) quickly and accurately [30]. The improvement of the website is not only seen as capable of delivering university information, products and services, but also a means of shaping the image of the university [9], [34]. By utilizing the opportunity of the web site, the university's prestige can be enhanced in the eyes of the world. in order to enhance the positive image of academic the usefulness of the university website is the most important aspect to evaluate in order to achieve high resilience in the digital environment and also increase the accessibility of the university website in search engines.

The development of IT-based networks and websites means an enticing opportunity to connect and disseminate sustainability initiatives in higher education institutions. Hence, the university web development must be compatible with a particular user need and also ensure that users are able to carry out activities on the website effectively without having any problems. This paper aims at analyzing and proposing the development of university websites that are ideally suited to enhancing dissemination of information and adding sustainable performance for their stakeholders. Therefore, the usability of the university website needs to be evaluated with important measurement aspects, so that the academic website can be widely evaluated by ensuring high efficiency of the university website in facilitating and disseminating information. This paper also provides a suitable model for assessing the use of educational websites as a framework for determining the effectiveness of institutional websites to continue the efficient distribution of information and user acceptance sustainability. The study also addressed questions focused on the study's objectives: i) What shortages do the university found in its current website?, ii) What aspects can the university website be improved? and iii) How can a university website be analyzed more comprehensively?

\section{$2 \quad$ Literature review}

Preliminary discussion of what constitutes a 'usable' website is a prerequisite to achieving the potential of a university website in an internet environment. According to a study by Junaini [24] university website plays an important role in promoting its institution. Therefore, the navigation and accessibility in using the website need to be properly display. One study on the university websites usefulness conducted by Dominic and Jati [12] indicates that most university websites in Malaysia are less concerned with quality and performance criteria. Manzoor \& Hussain [27] explain that the challenges faced by the Malaysian university web site effectiveness focus on three parts: i) the navigation system, ii) the information structure and iii) the content display. According to Jabar effandy et al [21], most university website development does not satisfy the user's needs, since the student's perspective is less applied in the design of university websites. Thus, understanding and addressing the website usability issue is important to help universities make their website more effectively. Highly productive university websites are important to look at a range of views of the number of user groups in connection with the platform, such as students, university employees and other stakeholders.

In addition to looking at navigation issues, the design [2] of the web also plays an important role, the attractive design will increase the university website usability to 
users. A modern, attractive, easy, clean, and consistent website design will enhance university communication with stakeholders. Affandy et al [2] and Affandy et al [3] argue that the usefulness of a website needs to look after the user needs and strives to meet user expectations with the appropriate design. In addition, designing a better website is likewise necessary to look at the stakeholder's point of view in order to achieve high usability [8], [15], [16]. Hence, the degree of university website usefulness depends on the intention and the user aim of enhancing the user experience. Thus, the purpose of a university website must directly act upon the user's specific needs, and must assure that the user meets the purpose and intention of completing the chore with the website. Usability is an important determinant of university website issues, and the main intention of increasing user commitment to university websites. As Al Mulhem [7], Astani \& Ethindi, [9] and Roy et al [29] point out, providing a university website that best satisfies the user needs, accessibility and information presentation that matches user expectations is one of the significant matters to look at to enhance the university's competitiveness. Yet, assessing the availability of university websites is a major and ongoing challenge for organizations to fill the needs and user experiences [12], [21]. As such, the website usability assessment has become an important study for obtaining data and information on the university's website effectiveness usage over time. Webometrics is a quantitative approach that can be used primarily to determine the usability of an academic website based on the structure, knowledge and technologies found in a publicly accessible website [18], [31], [33]. According to Ingwersen \& Björneborn [18] and Jhamb \& Ruhela [23], webometric analysis includes four main parts: website content analysis, web link structure analysis, web usage analysis (users' searching and browsing) and web technology analysis (performance). Furthermore, ISO / IEC 25010 [19] and ISO / IEC 25012 [20] outlined features that can be applied in website systems, particularly as guiding standards in website model development. In order to make the University Website more efficient, several website assessments have attempted to publish more important information in various respects, including the five main criteria set out by Hassan [15] as essential factors in university web analytics: organization, navigation, content, user-friendliness and design.

The above literature indicates that defining and assessing university website usability is highly relevant to design factors, development factors and user perception. This study examines the five main factors impacting the usability of university websites: i) Content and Organization Structure, ii) Linkages and Navigation, iii) Language, iv) Education Content and v) Option and Performance. This research also sees website design as a prevalent factor that can affect the high usage of university websites. Usability assessment results will be used to build high-impact university websites. This review intended provides useful information about current website challenges and which factors should be strengthened to help enhance website usability in the future.

\section{Methods}

In order to identify the attractiveness and the extensiveness of the website information, the researchers had gone through five ranked best university websites in the world, Asia and Malaysia based on the webometrics score. The next step is to rank the most 
important information based on sequence of appearance or visibility. Finally, questionnaire was distributed to the staff of the university in finding out their views.

This study used a random sampling method to obtain samples. Research is held out in the period from October to November 2019, with 350 valid questionnaires. The questionnaire was given out through Google Form. The study purported to assess user satisfaction by asking respondents to react to what they found and needed on the academy websites. The Likert Scale was used to measure the respondents' level of agreement by placing scale 1 as the lowest level and representing "strongly disagree" ratings, while scale 5 refers to the "strongly agree" rating.

The questionnaire consisted of five main aspects and a total of 23 questionnaire items were presented to the respondents. The first section aims to measure respondents' feedback on the content and organization structure of the university website, the second section was to measure respondents' expectations of the link and navigation aspects of the university website, the third section focuses on the level of language usage on the web site, the fourth section focuses on the aspect of education content presented on the university website and the last section focuses on the option and performance aspects of the web site. All data obtained will be analyzed using the statistical package for the social science (SPSS) program and the basic analysis used will be frequency analysis and percentage analysis.

\section{$4 \quad$ Results}

Analysis of the findings is intended to identify the effectiveness of the process of disseminating information (content and work processes) of the university website based on five key aspects: i) Content and Organization Structure, ii) Linkages and Navigation, iii) Language, iv ) Education Content and v) Option and Performance. The results showed that a total of $58.8 \%$ of female respondents and $41.7 \%$ of male respondents responded to this survey, with 155 (44.3\%) respondents from academic staff, 51 non-academic staff (14.6\%) respondents, $112(32 \%)$ graduate students and Postgraduate students accounted for $32(9.1 \%)$ of the respondents.

\subsection{Percentage analysis of results or content and organization aspects}

Table 1 shows the results of the percentage of respondents in terms of content and organizational structure. Out of the four items submitted, the overall majority of respondents were positive in favour of agreeing to the first, second and third items with $137(39.1 \%), 122(44.2 \%)$ and $145(41.4 \%)$ respondents responding to each item. The findings indicate that the university website portal works well with improving screen interface response time and link-to-screen links and enhancing the simplicity of obtaining info on the portal university website. 
Table 1. Total percentage of respondents response in terms of website content and organization aspects

\begin{tabular}{|l|l|c|c|c|c|c|}
\hline No. & \multicolumn{1}{|c|}{ Item } & SD & D & QA & A & SA \\
\hline 1. & $\begin{array}{l}\text { It is hard to find the information in a } \\
\text { timely manner }\end{array}$ & $2.3 \%$ & $34.0 \%$ & $\mathbf{3 9 . 1 \%}$ & $18.2 \%$ & $6.3 \%$ \\
\hline 2. & $\begin{array}{l}\text { It is not easy to find the information } \\
\text { I am looking for on the portal university } \\
\text { website }\end{array}$ & $3.7 \%$ & $35.0 \%$ & $\mathbf{4 4 . 2 \%}$ & $11.7 \%$ & $5.4 \%$ \\
\hline 3. & $\begin{array}{l}\text { The amount of waiting time before the } \\
\text { information appeared is acceptable }\end{array}$ & $6.6 \%$ & $22.6 \%$ & $\mathbf{4 1 . 4 \%}$ & $25.7 \%$ & $3.7 \%$ \\
\hline 4. & $\begin{array}{l}\text { The information in this website is } \\
\text { always not up-to-date }\end{array}$ & $4.3 \%$ & $\mathbf{3 8 . 0 \%}$ & $28.9 \%$ & $18.2 \%$ & $10.6 \%$ \\
\hline
\end{tabular}

Results from the analysis also found that the university website information provided to users was not updated with $101(28.9 \%)$ respondents expressly agreeing, followed by $64(18.2 \%)$ respondents and $87(10.6 \%)$ expressly agreeing with the statement. Based on the analysis, it has been shown that the web needs to update at all times in order to improve user usage.

\subsection{Percentage analysis of results or link and navigation aspects}

Table 2 presents the results of the percentage of respondents in terms of links and navigation. Grounded along the resolutions of the percentage acquired, found the majority of respondents, with $122(34.9 \%)$ is quite agree, $41(11.7 \%)$ agreed and 19 $(5.4 \%)$ strongly agree that the links on the academy website portal are not up to date. Links are provided also have fewer clear directions and less effective in in providing the information that consumers want, with the majority of the respondents showing a positive slope with 122 (35\%) respondents agreeing strongly, $41(11.7 \%)$ respondents agree and $19(5.4) \%$ ) respondents expressly agree. This suggests that information on a university website that can be effectively transmitted needs an up-to-date link to be able to convey data and direct users from page to page on a regular base and interact with it.

Table 2. Total percentage of respondents response in terms of linkages and navigation aspects

\begin{tabular}{|l|l|c|c|c|c|c|}
\hline No. & \multicolumn{1}{|c|}{ Item } & SD & D & QA & A & SA \\
\hline 1. & The links on this website are not updated & $3.7 \%$ & $\mathbf{4 4 . 3} \%$ & $34.9 \%$ & $11.7 \%$ & $5.4 \%$ \\
\hline 2. & $\begin{array}{l}\text { It is unclear which link will lead to the } \\
\text { information I am looking for }\end{array}$ & $4.0 \%$ & $\mathbf{3 6 . 6} \%$ & $35.4 \%$ & $18.6 \%$ & $5.4 \%$ \\
\hline 3. & I hard know where I am on this website & $7.4 \%$ & $\mathbf{4 2 . 9} \%$ & $31.1 \%$ & $14.9 \%$ & $3.7 \%$ \\
\hline 4. & $\begin{array}{l}\text { The website provides less useful cues and } \\
\text { links for me to get the desired information }\end{array}$ & $6.3 \%$ & $\mathbf{3 9 . 4 \%}$ & $34.6 \%$ & $14.1 \%$ & $5.7 \%$ \\
\hline
\end{tabular}


The provision of markers and links on the institute website portal was less regulated and less unionized and the majority of respondents showed a positive disposition towards the statement, by 121 (34.6\%) respondents expressing their agreement, $49(14.1 \%)$ agreeing and $20(5.7) \%)$ respondents again stated strongly agree. This indicates that the more appropriate arrangement will make the site more understandable and interesting. A systematic layout is required with the counsel of the appropriate markers to designate information that conforms to the user's demands.

\subsection{Percentage analysis of results for language aspects}

Regarding the language used in the academic website portal, 206 (58.9\%) respondents stated that the language used is clear and easy to understand and the information provided in English is easy to obtain with 199 (56.9\%) respondents giving preference positive for the statement (Refer to Table 3).

Table 3. Total percentage of respondents response in terms of language aspects

\begin{tabular}{|l|l|c|c|c|c|c|}
\hline No. & \multicolumn{1}{|c|}{ Item } & SD & D & QA & A & SA \\
\hline 1. & It is hard to read the content on this website & $11.1 \%$ & $\mathbf{5 8 . 9} \%$ & $19.7 \%$ & $6.6 \%$ & $3.7 \%$ \\
\hline 2. & $\begin{array}{l}\text { It is difficult to find the information in } \\
\text { English word }\end{array}$ & $11.7 \%$ & $\mathbf{5 6 . 9 \%}$ & $19.1 \%$ & $8.0 \%$ & $4.3 \%$ \\
\hline 3. & $\begin{array}{l}\text { This website offers less information } \\
\text { in dual languages }\end{array}$ & $7.7 \%$ & $\mathbf{4 3 . 4 \%}$ & $29.1 \%$ & $12.9 \%$ & $6.9 \%$ \\
\hline 4. & $\begin{array}{l}\text { The English information in this website is } \\
\text { always not updated }\end{array}$ & $7.7 \%$ & $\mathbf{4 7 . 4 \%}$ & $24.3 \%$ & $14.3 \%$ & $6.3 \%$ \\
\hline
\end{tabular}

With respect to the information displayed in two languages (Malay and English) website is less, by $24(6.9 \%)$ strongly agreed, 45 (12.9\%) agreed and $102(29.1 \%)$ of respondents who stated quite agree. The results of this analysis have shown that bilingual information may need further refinement. The information provided in English is always up to date. This shows that the use of simple and clear language can convey information more accurate and easier to understand.

\subsection{Percentage analysis of results for education content aspects}

Table 4 shows the percentage of respondents for Education Content aspects. Overall, $44(12.6 \%)$ respondents strongly disagreed and $118(38.7 \%)$ disagreed that "It is easy to identify the lecturers who teach any course". Based on the analysis obtained, the number of respondents who strongly agree that the university website portal is not regularly updated in terms of courses, event programs and staff information at the right time was $22(6.3 \%)$ and followed by $62(17.7 \%)$ agreeing, while $149(42.6 \%)$ of the respondents indicated a tendency to agree with the statement. This suggests that the contents in the university website portal should be constantly updated on the course, program and information staff to meet the interests of the university web page display to be achieved. 
Table 4. Total percentage of respondents response in terms of education content aspects

\begin{tabular}{|l|l|c|c|c|c|}
\hline No. & \multicolumn{1}{|c|}{ Item } & SD & D & QA & A \\
\hline 1. & $\begin{array}{l}\text { It is easy to identify the lecturers who teach } \\
\text { any course }\end{array}$ & $12.6 \%$ & $\mathbf{3 3 . 7 \%}$ & $31.7 \%$ & $17.7 \%$ \\
\hline 2. & $\begin{array}{l}\text { This website is irregularly updated in terms, of } \\
\text { course, event program and personnel information } \\
\text { in order to keep their information posted on } \\
\text { precise time }\end{array}$ & $4.0 \%$ & $29.4 \%$ & $\mathbf{4 2 . 6 \%}$ & $17.7 \%$ \\
\hline 3. & $\begin{array}{l}\text { The link does not direct us to the instructors' } \\
\text { office location, consultant hours, and the-mail } \\
\text { addresses }\end{array}$ & $4.3 \%$ & $27.7 \%$ & $\mathbf{4 4 . 0 \%}$ & $19.1 \%$ \\
\hline 4. & $\begin{array}{l}\text { This website will be more efficient if it provides } \\
\text { helpdesk live }\end{array}$ & $3.7 \%$ & $10.0 \%$ & $\mathbf{3 9 . 4 \%}$ & $27.1 \%$ \\
\hline
\end{tabular}

In summation, it was found that $154(44 \%)$ respondents strongly agreed, followed by $67(19.1 \%)$ agreeing and $17(4.9 \%)$ strongly agreeing that there was less clear connection to indicate the position of the teacher's office, consulting time and email address. The need to re-evaluate links and the layout of links that are more interactive and interesting and constantly updated is important to facilitate the delivery of learning and teaching information, academic information and event programs. The data analysis results also show that help with live helpdesk can enhance the strength of the university website portal in providing specific info and links on the web site to get good response from respondents with $138(39.4 \%)$ respondents agreeing, followed by $95(27.1 \%)$ agreed and 69 (19.7\%) strongly agreed with the assertion.

\subsection{Percentage analysis of results for option and performance aspects}

Overall, the results of the analysis obtained on options and performance of the university website portal indicate that improvements are needed. It was found that the majority of respondents answered positive questions for each question item. Table 5 shows the total percentage of respondents' responses to the Web site in terms of the Option and Performance.

Table 5. Total percentage of respondents response in terms of option and performance aspects

\begin{tabular}{|l|l|c|c|c|c|c|}
\hline No. & \multicolumn{1}{|c|}{ Item } & SD & D & QA & A & SA \\
\hline 1. & $\begin{array}{l}\text { The search option on this website always } \\
\text { show up irrelevant results }\end{array}$ & $5.4 \%$ & $\mathbf{4 6 \%}$ & $32.0 \%$ & $13.4 \%$ & $3.1 \%$ \\
\hline 2. & $\begin{array}{l}\text { It takes a long time download a file or to go } \\
\text { to a particular page }\end{array}$ & $6.9 \%$ & $\mathbf{4 1 . 4 \%}$ & $33.7 \%$ & $13.1 \%$ & $4.9 \%$ \\
\hline 3. & $\begin{array}{l}\text { I feel that the website should have one more } \\
\text { special function }\end{array}$ & $2.9 \%$ & $14.0 \%$ & $\mathbf{4 3 . 7 \%}$ & $23.1 \%$ & $16.2 \%$ \\
\hline
\end{tabular}

Based on the items submitted, the lookup for information (search option) are irrelevant in which it gained a total of $112(32 \%)$ stated quite agree followed by $47(13.4 \%)$ of respondents agreed and $11(3.1 \%)$ again answered strongly agree. The second and third question referring to the slow downloading of information or reaching for the 
required information, results show, each found $118(33.7 \%)$ and $153(43.7 \%)$ of quite agree with that statement. This point out that the suitability of the information search in the university website portal needs to be improved the effectiveness of the process of distribution and information delivery network academic web.

\section{$5 \quad$ Results and discussion}

The analysis of the feedback on the website display outlines some suggestions and improvements needed to enhance the capabilities and effectiveness of the university website to convey information to users. In line with the ever-updated content of information content, the emphasis is on the importance of orderly and structured links that facilitate the spreading of information and reason. Through well-organized links and markers, these can give users a clearer picture and channel of information. Additional suggestions with links and navigation available on the website should be minimised in order to increase the time it needs to find the information required.

In terms of language, there is still less bilingual information found in the website. The role of bilingualism is very important in conveying information [28]. Applying the appropriate language on a web page will indirectly help users understand and remember something. Existing practices require an English language specialist to supply information in fast time and instantly uploaded. The appropriate web presentation design and live helpdesk concept enable users to obtain information rapidly and incisively. The environment and disclosure of the academic portal website should offer more input to links to information about academics such as faculty, department locations, consulting time and email address. Based on the feedback received, there is a need for high links in terms of learning and teaching information, academic information and event programs to help users get the most up-to-date and up-to-date information as they exchange semesters. Overall, the analysis indicates that the university website needs to be more explicit in terms of the concept of data dissemination through interactive means and the use of components such as links, live help desk, and good navigation that indirectly provide an easier means of giving up information and accelerate up the operation of receiving information.

Figure 1 provides a set of general guidelines for the development of university websites and shows a guide model consisting of the university websites factors, websites inspection approach's and usability aspects. Content and organization, linkages and navigation, option and performance, language, education content and attractiveness layout. This characterization factor can be used as a reference and can also be used to evaluate website usability level. Each of these factors is explained as follows:

Content and Organization This factor emphasizes the degree of continuity and order of the information presented on the website that is hierarchically ordered as well as the usefulness and the thrust of the information transmitted by the website. That contain information that need be consequences for targeted groups such as students, staffs, parents and other stakeholders. The vital information presented should be aligned and up-to-date, allowing individuals to receive real-time information. 
Linkages and Navigation

Language

Education Content

Option and Performance

Attractiveness Layout
Focusing on the degree of mechanisms relating to: (i) all links are effective works, (ii) main controls capable of performing a navigation-oriented function, (iii) all links support navigation across the correct web screens and connect to each other in the pages, (iv) allow 'easiness' surfing to the target location, and (v) allow all rollovers to operate and return to 'homepage.'

To achieve globalization, the use of multiple language versions of the display, such as the Malay and English languages or bilingual to enhance knowledge transmission is particularly essential for international students. The accessibility of language is to support the idea that the website of the university will make it easier for users to access what they need or want from the website, and that the website of the university that 'can speak the language understood by the respondent' can accommodate users' needs.

For university websites, the important concept is to enable users to obtain educational information more effectively and interestingly. This aspect emphasizes the features of educational information that the website requires to provide users with useful information before accessing the website, browsing the website and visiting the website. The value of educational content is: i) providing online data and information (registration and payment), ii) providing prospectus-related information to allow students to carefully select their programs and courses, and sharing educator's information to enable stakeholders to know more about potential collaborative lecturers.

Signifies the responsiveness and consistency of university website performance. Specifically about loading speed and network speed. The websites were considered to be delivering information in real time conditions. As a requirement of high compatibility, websites had to be able to openness by various browsers and with the ability to work in different versions (old or current) system. Search options like option search, advanced search or semantic search on pages should be provided with intended efficient searchable. Daily support should be offered to provide sufficient assistance with current website interactions, such as help desk live.

Visually, a pleasant website's appearance draws users 'attention. One of the significant factors increasing the usability of this university website is the attractive design of the website. Appropriate knowledge visualization can 
enhance cognitive mapping. Visuals such as the use of images, multimedia (video, pictures and animations), visual quality, colour should be adapted in order to make the university website more appealing.

The website inspection approaches are used to test the website prototype before the actual university website is launched. It is proposed that there are three inspection methods to be performed, including: i) cognitive walkthrough [14], [25] is an evaluation of usability and website interaction facilities undertaken by a group of reviewers; ii) heuristic evaluation [13] is one approach to testing the usability of the website, in particular to design concepts and interface display before the site is made public and iii) user testing review [25], [26] provide direct information on how users interact with the university website and the actual problems encountered during website interactions. The respondents for this approach were usually the general public or real users. This analysis obtains user feedback (respondent) through questionnaires or direct user interviews. The inspection approach is essential to ensure the usability of the university website on the strength of the six main factors on the university website. Disciplines that provide standardized strategies to achieve usability of university websites need to be addressed in terms of functions, mechanisms, and interface design. University website usability shall be properly reviewed and gained from the perspective of:

\section{i) User's satisfaction}

To achieve the highest performance and productivity when using the websites, user satisfaction [6], [10], [17], [32] and experience should be a priority. The university website's capacity is linked to achieving a reasonable degree of user satisfaction and acceptable to use the university website to accomplish the goal efficiently and effectively. When users achieve high satisfaction, they are more comfortable with the website, and users feel individuals can find information with encouragement and pleasant.

\section{ii) Accessibility}

Accessibility [1], [4] in use is essential in seeing university websites' productivity. Web sites respond at reasonable speed, by providing influential stakeholders highcapacity assessments. Strong functionality helps users to operate any interaction acts, information, and functions with a quick and enjoyable visit. Accessibility aims to attain convenience, timeliness or effort by effectively achieving website efficiency.

\section{iii) Interactivity}

Interactivity [11], [22] refers to a website's ability to connect and communicate with users to achieve the website's usability. Immediate feedback will increase website user mastery functionality and level. When the university website is well run, it indicates that the website interacts at a reasonable speed and easily gets what they want. Users also have strong control over the university website as they are able to communicate with a good level in the website area. 


\section{iv) Sustainability}

Sustainability is the key to academic web performance, long-term sustainability will lead to successful communication with stakeholder perceptions, site layout and content. Sustainable university web design is a practice to improve capacity to maintain current and future stakeholders' needs.

Therefore, studying users is essential to review user satisfaction with the usability of the university website achieved where clear navigation arrangements and creative design can provide users with comprehension and ease of educational information and enhance user experience on the university website. It is to deliver a pleasant experience, easy access, and time-saving to give users enjoyment and positive attention.

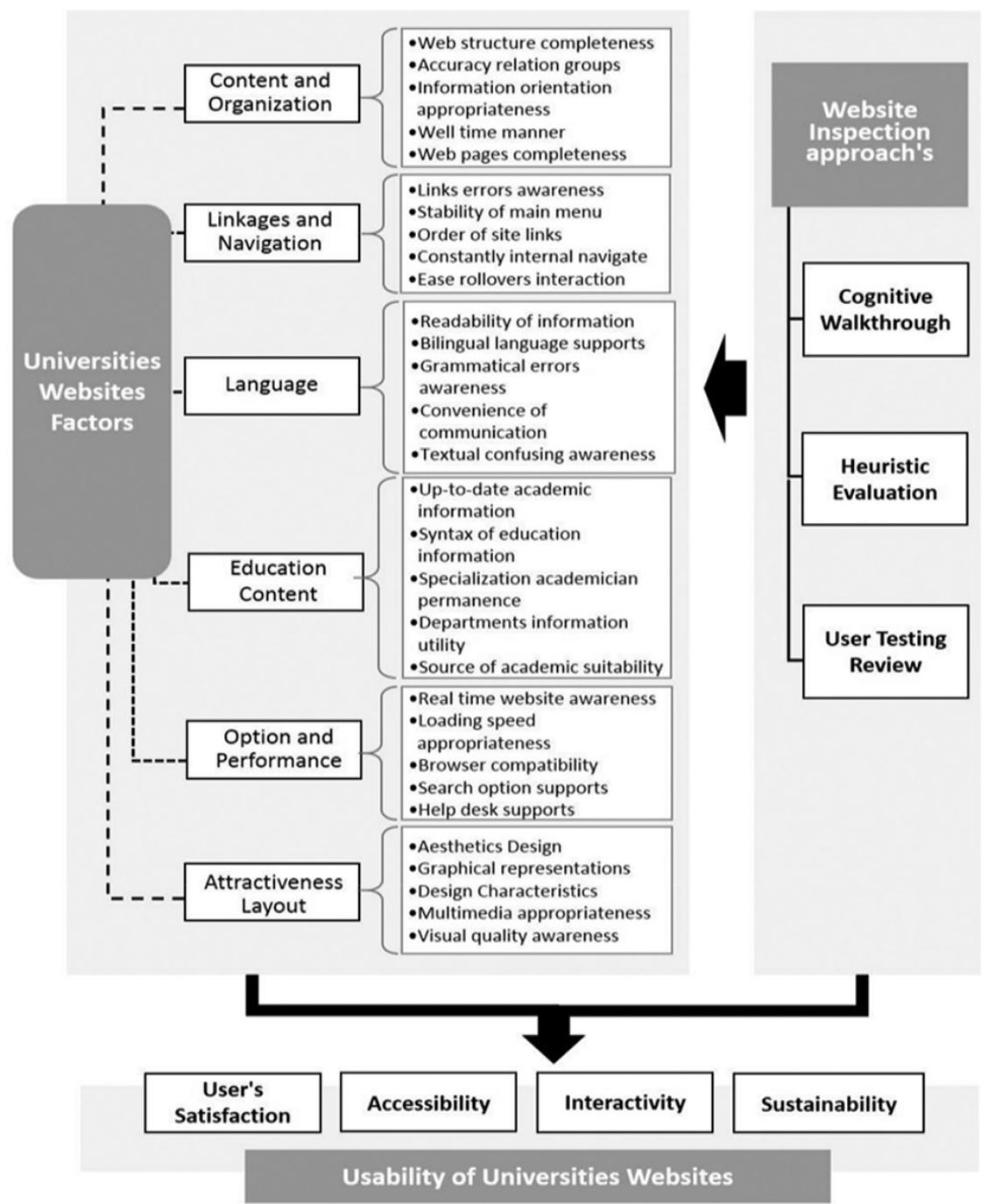

Fig. 1. Proposed outlines university website development approach 


\section{Conclusion}

The university website serves as a platform for stakeholders (students, administrative staff, academic staff and other users) to get the latest information from the university administration. The usefulness of the website plays an important role in establishing good and healthy communication between the university and its stakeholders, where a healthy communication between the university management and stakeholders can contribute to the efficient management of university affairs. Consequently, listening to the needs of stakeholders will give designers an opportunity to create a better web page layout. Relevant web content helps users easily find information. Focusing on and evaluating stakeholder perceptions will contribute to the strength of the university websites. Involvement of stakeholders' suggestions and prospects is important to be part of the decision-making process of building a university website that is tailored to a diverse target audience.

A set of general guidelines has been proposed in this study, where consistent design and ease of navigation are used to enhance the user experience of the university websites visually, interactively and visually. It also ensures easy access to information, saves time for users and brings a pleasant user experience. Therefore, to meet the ever-changing user preferences, time distribution and improving the usability of the website, user perception surveys to be implemented from time to time, where continuous feedback from users provides valuable input to universities to improve their website. Therefore, the website should be thoughtfully chosen, as the university website also gives the user a first impression on the university. University websites play a significant role in encouraging two key points. Firstly, to facilitate communication and interaction activity to increase stakeholder trust, including prospective students, current students, alumni on the website. Secondly, a strong university website helps university employees to work more efficiently. Eventually, to improve the website's efficiency and provide better outcomes for the university. The ideal university website should have an attractive and friendly interface, and provide users with all necessary information and services. Eventually, the ideal university website should have an attractive, easy to use interface and be capable of delivering all the information and resources required and expected to improve the usability of the website and to produce a greater utility for the users.

\section{$7 \quad$ Acknowledgement}

Special thanks to Creative Industry International Conference (CIIC) 2020 organised by School of Creative Industry Management and Performing Arts, Universiti Utara Malaysia.

\section{References}

[1] Abuaddous, H.Y., Jali, M.Z., \& Basir, N. (2016). Web Accessibility Challenges. International Journal of Advanced Computer Science and Applications (IJACSA), 7, 172-181. https://doi.org/10.14569/IJACSA.2016.071023 
[2] Affandy, H., Hussain, A., \& Nadzir, M. (2016). Web Visual Design Principle Used in Public Universities Website Design. Proceedings of the 3rd International Conference on Applied Science and Technology (ICAST'18).

[3] Affandy, H., Hussain, A., \& Nadzir, M. (2019). A New Set of Attributes to Integrate Web Usability and Web Aesthetics in the Scope of Public Universities Websites. International Journal of Innovative Technology and Exploring Engineering (IJITEE), 8(8), 247-250.

[4] Ahmi, A., \& Rosli, M. (2015). Web Accessibility of the Malaysian Public University Websites. Proceedings of the International Conference On E-Commerce, 20-22 Oct, Kuching, Sarawak, Malaysia.

[5] Ahmi, A., \& Rosli, M. (2016). Evaluating Accessibility of Malaysian Public Universities Websites using AChecker and WAVE. Journal of Information and Communication Technology. https://doi.org/10.2139/ssrn.3550314

[6] Akilli, G. (2002). User Satisfaction Evaluation of an Educational Website. Turk. Online Journal of Educational Technology, 4(1), 85-92.

[7] Al Mulhem, A. (2020). Exploring the Key Factors in the Use of an E-Learning System Among Students at King Faisal University, Saudi Arabia. International Journal of Interactive Mobile Technologies (iJIM), 14(3), 19-37. https://doi.org/10.3991/ijim.v14i03.11576

[8] Alshira'H, M. (2020). The Effects of Usability and Accessibility for E-Government Services on the End-user Satisfaction. International Journal of Interactive Mobile Technologies (iJIM), 14(13), 78-90. https://doi.org/10.3991/ijim.v14i13.14659

[9] Astani, M., \& Elhindi, M. (2008). An Empirical Study of University Websites. Issues in Information Systems, IX(2), 460-465. https://doi.org/10.48009/2 iis 2008 460-465

[10] Bauk, S., Snežana, Š., \& Kopp, M. (2014). Estimating Students' Satisfaction with Web Based Learning System in Blended Learning Environment. Education Research International, 2014(2014), 1-11. https://doi.org/10.1155/2014/731720

[11] Bodomo, A. (2010). Strategies for Enhancing and Evaluating Interactivity in Web-Based Learning and Teaching. International Journal of Web-Based Learning and Teaching Technologies, 5(4), 18-43. https://doi.org/10.4018/jwltt.2010100102

[12] Dominic. D., \& Jati. H., (2010). Evaluation Method of Malaysian University Website: Quality Website Using Hybrid Method. International Symposium on Information Technology, Kuala Lumpur, 1-6. https://doi.org/10.1109/ITSIM.2010.5561363

[13] Fichter, D. (2001). Testing the Website Usability Waters. Online (Weston, Conn.), 25(2), 78-80.

[14] Gonzalez, M., Granollers, T., \& Pascual, A. (2008). Testing Website Usability in Spanish-Speaking Academia through Heuristic Evaluation and Cognitive Walkthrough. Journal of Universal Computer Sciences, 14(9), 1513-1528. https://doi.org/10.3217/jucs$\underline{014-09-1513}$

[15] Hasan, L. (2012). Investigating the Relative Importance of Design Criteria in the Evaluation of the Usability of Educational Websites from the Viewpoint of Students, in the Proceedings of the World Congress on Engineering (WCE 2012), Vol II, London, UK, 4-6 July.

[16] Hassan, L. (2013). Heuristic Evaluation of Three Jordanian University Websites. Journal of Informatics in Education, 12(2), 231-251. https://doi.org/10.15388/infedu.2013.16

[17] Imlawi, J. (2017). Health Website Success: User Engagement in Health-Related Websites. International Journal of Interactive Mobile Technologies (iJIM), 11(6), 9-64. https://doi. org/10.3991/ijim.v11i6.6959

[18] Ingwersen P., \& Björneborn L. (2004) Methodological Issues of Webometric Studies. In: Moed H.F., Glänzel W., \& Schmoch U. (Eds), Handbook of Quantitative Science and Technology Research. Springer, Dordrecht. https://doi.org/10.1007/1-4020-2755-9 16

[19] ISO/IEC 25010. (2011). Systems and Software Engineering - Systems and Software Quality Requirements and Evaluation (Square) - System and Software Quality Models. 
[20] ISO/IEC 25012. (2008). Software Engineering - Software Product Quality Requirements and Evaluation (SQuaRE) - Data Quality Model. http://www.iso.org/iso/catalogue detail. htm?csnumber $=35736$. Accessed 05 June 2020.

[21] Jabar, M., Usman, U., \& Awal, A. (2013). Assessing the Usability of University Websites from Users' Perspective. Australian Journal of Basic and Applied Sciences, 7(10), 98-111.

[22] Jano, Z., Hussin, H., Abdullah, A., \& Cheong, K.M. (2015). Website Interactivity in Malaysia and Australian Universities. Asian Social Science, 11(17), 14-21. https://doi.org/10.5539/ ass.v11n17p14

[23] Jhamb, G., \& Ruhela, A. (2017). A Webometric Study of the Website of Public Libraries. International Journal of Library and Information Studies, 7(4), 83-89.

[24] Junaini, N. (2002). Navigation Design and Accessibility Evaluation of the Malaysian Public University Homepage. In Proceedings of the Second National Conference on Cognitive Science (CSC2002), Kuching, Sarawak, Malaysia, 181-189.

[25] Lazar (2001). User-Centered Web Development. Boston: Jones and Bartlett.

[26] Lynch, P., \& Horton, S. (2008). Web Style Guide: Basic Principles for Creating Web Sites (3rd ed.). New Haven, CT: Yale University Press.

[27] Manzoor, M., \& Hussain, W. (2012). A Web Usability Evaluation Model for Higher Education Providing Universities of Asia. Sci Tech and Development, 31(2), 183-192.

[28] Miraz, H., Ali, M., \& Excell, P. (2017). Multilingual Website Usability Analysis Based on an International User Survey. arXiv preprintarXiv:1708.05085.

[29] Roy, S., Pattnaik, P., \& Mall, R. (2014). A Quantitative Approach to Evaluate Usability of Academic Websites Based on Human Perception. Egyptian Informatics Journal, 15(3), 159-167. https://doi.org/10.1016/j.eij.2014.08.002

[30] Sengel, E. (2013). Usability Level of a University Web Site. Procedia-Social and Behavioral Sciences, 106, 3246-3252. https://doi.org/10.1016/j.sbspro.2013.12.373

[31] Shahruddin, S.S., Chik, R.Z.W., \& Malik, I.S.A. (2019). Visibility Study in Strategizing for Web Marketing and Webometric University Ranking in Malaysia. Journal of Physics: Conference Series, 1193(1), 012002. https://doi.org/10.1088/1742-6596/1193/1/012002

[32] Tahir, U., \& Mushtaq, A. (2015). Measuring User Satisfaction through Website Evaluation Framework. International Journal of Knowledge Engineering, 1(2), 125-128. https://doi. org/10.7763/IJKE.2015.V1.21

[33] Thelwall, M. (2009). Introduction to Webometrics: Quantitative Web Research for the Social Sciences. Synthesis Lectures on Information Concepts, Retrieval, and Services. Morgan \& Claypool, 1-116. https://doi.org/10.2200/S00176ED1V01Y200903ICR004

[34] Undu, A., \& Akuma, S. (2018). Investigating the Usability of a University Website from the Users' Perspective: An Empirical Study of Benue State University Website. International Journal of Computer and information Engineering, 12(10), 922-929.

\section{Authors}

Lilian Lee Shiau Gee is a lecturer and currently attached to the Visual Art Technology Programme, Universiti Malaysia Sabah. Her research interests are in experience studies and looking at the relationship of the visual design for human perception and emotion in creative developments. She practiced cross disciplines and collaborative, enriching visual design as a platform, fostered by advanced technologies. E-mail: lilian@ums.edu.my 
Jakaria Dasan is currently attached as a director and a senior lecturer, as well as actively involved in researches activities that have contributed to his thorough understanding of human resource management. In addition, He is investing his expertise and skills in developing the socio-economic of the rural community under the University for Society program in northern Borneo.

Che Hasruddin Che Hasan was Corporate Relations Division officer at Universiti Malaysia Sabah. He did a lot of research and writing in the field of publishing, film, and ethnic culture in Sabah. His areas of expertise are photography and printing. E-mail: chehasruddin@ums.edu.my

Article submitted 2021-05-04. Resubmitted 2021-06-15. Final acceptance 2021-06-28. Final version published as submitted by the authors. 